\title{
Refractory malignant hepatocellular tumor consisting of hepatocellular carcinoma and hepatoblastoma in a 10-year-old male
}

\author{
Minako Sugiyama ${ }^{1}$, Shinsuke Hirabayashi ${ }^{1}$, Yukayo Terashita ${ }^{2}$, Yuko Cho ${ }^{1}$, Akihiro Iguchi ${ }^{1}$, \\ Yoshihito Ohhara ${ }^{3}$, Daisuke Abo ${ }^{1}$, Shohei Honda ${ }^{1}$, Emi Takakuwa ${ }^{4}$, and Atsushi Manabe ${ }^{1}$ \\ ${ }^{1}$ Hokkaido University Graduate School of Medicine \\ ${ }^{2}$ Hokkaido University Graduate School of Medicine School of Medicine \\ ${ }^{3}$ Faculty of Medicine and Graduate School of Medicine, Hokkaido University \\ ${ }^{4}$ Hokkaido University Hospital
}

June 22, 2020

\begin{abstract}
Although hepatoblastoma constitutes most of hapetic tumours in chidren, other types of tumors are often observed in older patients. We report a case of a 10-year-old Japanese boy with a transitional hepatic tumour consisting of both hepatoblastoma and hepatocellular carcinoma. After surgery and chemotherapy with cisplatin and pirarubicin, the tumour regressed, however, new tumours in the liver evolved with element of hepatocellular carcinoma. He died as a result of hepatic failure afte lenvatinib and drug-eluting transcatheter arterial chemoembolisation 18 months after diagnosis. Examinations of a panel of genomic alterations did not identify any therapeutic targets.
\end{abstract}

\section{Introduction}

More than $90 \%$ of hepatic malignant tumours in paediatric patient are hepatoblastomas. However, we should suspect of hepatocellular carcinoma (HCC) if a patient is older than 10 years old ${ }^{1)}$. Although most HCCs in adult patients are associated with hepatitis $\mathrm{B}$ virus, hepatitis $\mathrm{C}$ virus or alcoholic and non-alcoholic fatty liver disease, the causes of HCC in paediatric patients remain unclear ${ }^{1), 2)}$. In adult patients with HCC, hepatectomy, radiofrequency ablation, transcatheter arterial chemoemboliasation (TACE), and liver transplantation are treatment options ${ }^{2}$. Recently, multikinase inhibitors, including sorafenib and lenvatinib, were approved for treatment of those with $\mathrm{HCC}^{3)}$. However, a therapeutic strategy for paediatric patients with HCC has not yet been established. In addition, pathological examination often reveals variations, including fibrolamellar type, epithelial type and clear cell carcinoma ${ }^{1)}$. Transitional hepatic tumours, which have components of both HCC and hepatoblastoma, were also reported in paediatric patients ${ }^{4), 5)}$. We report a case of refractory transitional hepatic tumour.

\section{Case presentation}

A 10-year-old Japanese boy presented to our department with intense abdominal pain, frequent vomiting, and hypotension (blood pressure, $76 / 49 \mathrm{mmHg}$ ). The laboratory findings were as follows: white blood cell count, $20.1 \times 10^{9} / \mathrm{L}$; red blood cell count, $2.47 \times 10^{12} / \mathrm{L}$; haematocrit, $20.3 \%$; haemoglobin, $6.8 \mathrm{~g} / \mathrm{dL}$ and platelet count, $33.8 \times 10^{9} / \mathrm{L}$; C-reactive protein, $0.11 \mathrm{mg} / \mathrm{dL}$; aspartate aminotransferase, $86 \mathrm{U} / \mathrm{L}$; alanine aminotransferase, $20 \mathrm{U} / \mathrm{L}$; lactate dehydrogenase, $351 \mathrm{U} / \mathrm{L}$; uretic acid, $8.0 \mathrm{mg} / \mathrm{dL}$; alpha fetoprotein (AFP), $3615 \mathrm{ng} / \mathrm{ml}$ and protein induced by vitamin K absence-II, $1493 \mathrm{mAU} / \mathrm{ml}$. Computed tomography (CT) scan revealed a tumour of 8.5 inches in diameter in the right hepatic lobe and massive ascites (Figure1. a, b), suggesting bleeding from a ruptured tumour. The patient undewent emergent coil embolisation of hepatic arteries of segment 5 and segment 6 . After 6 days, a complete tumour resection was performed by partial 
hepatectomy by paediatric surgeons. Pathological examination revealed an HCC with negative margin, and the HCC cells were not identified in the ascite. Although the patient's AFP level decreased to $56 \mathrm{ng} / \mathrm{ml} 45$ days after the surgery, it increased again to $135 \mathrm{ng} / \mathrm{ml}$ with a small nodule at lower surface of the liver and right lung field, as seen on CT scan. Fluorine-18-fluorodeoxyglucose (FDG) positron-emission tomography (PET)-CT showed mild accumulation of FDG in the nodules. Pathological review of the ruptured tumour revealed a malignant hepatocellular tumour consisting of both HCC and hepatoblastoma (Figure 2. a). Two months after the surgery, the patient received the first course of CITA (cisplatin and pirarubicin ), consisting of $16 \mathrm{mg} / \mathrm{m}^{2} /$ day of cisplatin div on days 1 to 5 and $30 \mathrm{mg} / \mathrm{m}^{2}$ /day of pirarubicin on days 2 and 3 . After 2 courses of CITA, the patient's AFP level decreased to $28 \mathrm{ng} / \mathrm{ml}$, and CT showed no lesion. After the sixth course of CITA, AFP level decreased to $6 \mathrm{ng} / \mathrm{ml}$. However, after the seventh course of CITA, the patient's AFP level increased to $31 \mathrm{ng} / \mathrm{ml}$ with no lesion shown on CT and FDG PET-CT. Two months later, AFP level increased to $302 \mathrm{ng} / \mathrm{ml}$, and CT revealed a nodule at the lower surface of the liver. The lesion was resected by paediatric surgeons, and pathological examination revealed mainly HCC (Figure 2. b). AFP level further increased and multiple lesions in the bilateral lobes of liver developed (Figure1.c,d). Finally, lenvatinib was administered and drug-eluting beads TACE with epirubicine was performed by interventional radiologists. A panel of oncogenes were tested and no actionable targets were identified though ATRX splice site $370+1 \mathrm{G}>\mathrm{T}$ was noted as an oncogenic mutation. The patient died as a result of hepatic failure. The total duration of clinical course was 18 months.

\section{Discussion}

Several clinical studies reporting hepatoblastomas have constructed a therapeutic strategy consiting mainly of chemothrapy and surgery ${ }^{6)-9)}$. A chemotherapy course composed of platinum and anthracycline has been used as a standard treatment ${ }^{6), 7)}$. An appropriate chemotherapeutic regimen for paeditric patients with HCC has not been established because the number of the cases is low and pathological findings are different from that of adults. Indeed, progonosis for the patients remains poor ${ }^{10)}$. In parallel, HCCs in paediatric patients may not be biologically similar to HCCs in adult patients ${ }^{1)}$. In the current case, pathological examination review revealed a malignant hepatic tumour consisting of HCC and hepatoblastoma. That is, the tumour had regions of HCC and lesions of hepatoblastoma. Prokurat et al. ${ }^{4)}$ and Ozcan et al. ${ }^{5)}$ reported cases of the hepatic tumours, such as transitional liver cell tumours, which were structured by the components of both HCC and hepatoblastoma.

In the current case, CITA chemotherapy decreased the AFP level slowly, and lesions by CT resolved. It suggested that CITA was effective for the components of hepatoblastoma. Then, the patient's serum AFP increased again and it was caused by enlargement of HCC component, which was revealed by the pathological findings of the specimen obtained at the second surgery. Lenvatinib has recently been approved for treatment of HCCs in Japan because it was reported that lenvatinib was non-inferior to sorafenib in overall survival in advanced $\mathrm{HCC}$ in adult patients ${ }^{3)}$. Conceivably, administering a multikinase inhibitor, such as lenvatinib, combimed with CITA, might be able to control HCC components although the utility of this combination was not reported previously. We tried lenvatinib after relapse of the disease and a positive effect was not observed.

Genomic variations have also been revealed in hepatic tumours ${ }^{11), 12)}$. In the current case, the results of the oncogene panel did not show any actionable variation. ATRX splice site mutation observed in our patient was reported in also low-grade glioma ${ }^{13)}$, but not in HCC. Differential analysis of a panel of oncogenic mutations may clarify the similarity and difference in hepatic tumors of children and adults.

\section{Conflicts of interest}

The authors declare no conflicts of interest.

\section{Acknowledgments}

We thank all radiotherapists and paediatric surgeons who performed arterial emborization and surgery. Medical oncologists advised us on the use of multi-kinase inhibitor. Paediatricians performed examinations, 
and whose comments and suggestions were of inestimable value for the case and clinical practices.

\section{References}

1 Khanna R, Verma SK. Pediatric hepatocellular carcinoma. World J Gastroenterol 2018;24:3980-3999.

2 Kulik L, El-Serag HB. Epidemiology and management of hepatocellular carcinoma. Gastroenterology $2019 ; 156: 477-491$.

3 Kudo M, Fin RS, Qin S, Han KH, Ikeda K, Piscaglia F, Baron Ari, Park JW, Han G, Jassem J, Blanc J-F, Vogel A, Komov D, Evans TR-J, Lopez C, Dutcus C, Guo M, Saito K, Kraljevic S, Tamai T, Ren M, Cheng A-L. Lenvatinib versus sorafenib in first-line treatment of patients with unresectable hepatocellular carcinoma: a randomised phase 3 non-inferiority trial. Lancet 2018;391:1163-1173.

4 Prokurat A, Kluge P, Kosciesza A, Perek D, Kappeler A, Zimmermann A. Transitional liver cell tumor (TLCT) in older children and adolescents: A novel group of aggressive hepatic tumors expressing betacatenin. Med Pediatr Oncol 2002;39:510-518.

5 H N Ozcan, B Oguz, T Salim, B Talim, M Halilogu. A rare malignant hepatic tumor of childhood: Transisional liver cell tumor revisited. JBR-BTR 2015;98:79-81.

6 F Sasaki, T Matsunaga, M Iwafuchi, Y Hayashi, H Ohkawa, M Ohira, T Okamatsu, T Sugito, Y Tsuchida, A Toyosaka, N Nagahara, H Nishihira, Y Hata, J Uvhino, K Misugi, N Ohnuma, (Japanese Study Group for Pediatric Liver Tumor). Outcome of hepatoblastoma treated with the JPLT-1 (Japanese Study Group for Pediatric Liver Tumor) Protocol-1: A report from the Japanese Study Group for Pediatric Liver Tumor. J Pediatr Surg 2002;37:851-856.

7 G Perilongo, E shafford, R Maibach, D Aronson, L Brugieres, P Brock, M Childs, P Czauderna, G MacKinlay, J Pritchard, R Rondelli, M Scopinaro, C staalman, J Plaschkes, International Society of Pediatric Oncology-SIOPEL2. Risk-adapted treatment for childhood hepatoblastoma final report of the second study of the International Society of Paediatric Oncology_SIOPEL 2. Eur J Cancer 2004;40:411-421.

8 P F Ehrich, M L Greenberg, R M Filler. Improved long-term survival with preoperative chemotherapy for hepatoblastoma. J Pediatr Surg 1997;32:999-1002.

9 Marcio H Malogolowkin, Howard M Katzenstein, Rebecka L Meyers, Mark Krailo, Jon M Rowland, Joel Haas, Milton J Finegold. Complete surgical resection is curative for children with hepatoblastoma with pure fetal histology: A report from the Children's Oncology Group. J Clin Oncol 2011;29:3301-3306.

10 Katzenstein HM, Krailo MD, Malogolowkin MH, Ortega JA, Liu-Mares W, Douglass EC, Feusner JH, Reynolds M, Quinn JJ, Newman K, Finegold MJ, Haas JE, Sensel MG, Castleberry RP, Browman LC. Hepatocellular carcinoma in children and adolescents: results from the Pediatric Oncology Group and the Children's Cancer Group Intergroup Study. J Clin Oncol 2002;20:2789-2797.

11 Haines K, Sarabia SF, Alvarez KR, Tomlinson G, Vasudevan SA, Heczey AA, Roy A, Finegold MJ, Parsons DW, Plon SE, Lopez-Terrada D. Characterization of pediatric hepatocellular carcinoma reveals genomic heterogeneity and diverse signaling pathway activation. 2019. Pediatr Blood Cancer 2019;66:doi: $10.1002 /$ pbc. 27745 .

12 Yamaoka H, Ohtsu K, Sueda T, Yokoyama T, Hiyama E. Diagnostic and prognostic impact of beta-catenin alterations in pediatric liver tumors. Oncol Rep 2006;15:551-556.

13 Jayasinghe RG, Cao S, Gao Q, Wendl MC, Vo NS, Reynolds SM, Zhao Y, Climente-González H, Chai S, Wang F, Varghese R, Huang M, Liang WW, Wyczalkowski MA, Sengupta S, Li Z, Payne SH, Feny D, Miner JH, Walter MJ, Cancer Genome Atlas Reseach Network; Vincent B, Eyras E, Chen K, Shmulevich I, Chen F, Ding L. Systematic analysis of splice-site-creating mutations in cancer. 2018 Cell Rep 2018;23:270-281.e3.

\section{FIgure LegendS}


Figure 1. a,b. Contrast enhaced CT scan revealed hepatic tumour in the right hepatic lobe and ascites at the diagnosis. The patient was not able to lie spine because of abdominal pain. c. MRI findings; dynamic T1-weighted showed multiple disseminations as low-intensity area within hepatic lobe 4 months after the last course of CITA. d. Then, there was FDG accumulation in the lesions by FDG PET-CT.

Figure 2. a . The specimen resected by the first surgery. Pathological examination (Hematoxylin and Eosin) showed the resions of HCC and hepatoblastoma. The left half of the picture showed the component of HCC, the cells with high nucleus-cytoplasmic ratio. And the right is hepatoblastoma, the cells with a large central eosinophilic nucleolus and a clear cytoplasm. b. The specimen resected at the relapse revealed mainly HCC.
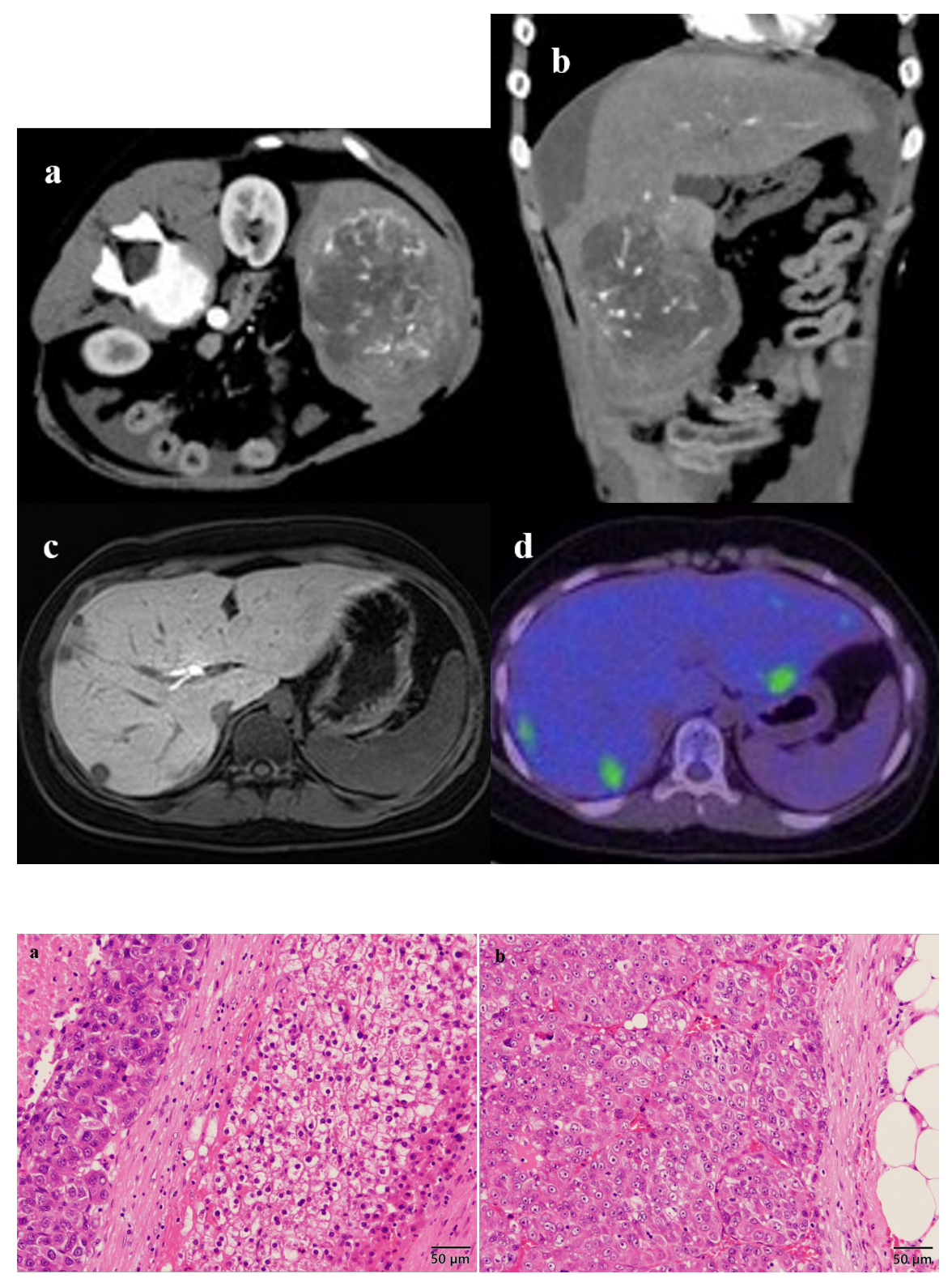